\title{
Response Adaptation in Barrel Cortical Neurons Facilitates Stimulus Detection during Rhythmic Whisker Stimulation in Anesthetized Mice
}

\author{
(1) Natali Barros-Zulaica, ${ }^{1,2}$ (1) Alessandro E. P. Villa, ${ }^{3}$ and ${ }^{\text {(1) Angel Nuñez }}{ }^{1}$
}

https://doi.org/10.1523/ENEURO.0471-18.2019

\begin{abstract}
${ }^{1}$ Departamento de Anatomía, Histología y Neurociencia, Facultad de Medicina, Universidad Autónoma de Madrid, Madrid 28029, Spain, Blue Brain Project; École Polytechnique Fédéral de Lausanne, 1015 Lausanne, Switzerland, and ${ }^{3}$ Laboratoire de Neuroheuristique, Groupe de Recherche en, Science de la Complexité, Université de Lausanne, 1015 Lausanne, Switzerland
\end{abstract}

\begin{abstract}
Rodents use rhythmic whisker movements at frequencies between 4 and $12 \mathrm{~Hz}$ to sense the environment that will be disturbed when the animal touches an object. The aim of this work is to study the response adaptation to rhythmic whisker stimulation trains at $4 \mathrm{~Hz}$ in the barrel cortex and the sensitivity of cortical neurons to changes in the timing of the stimulation pattern. Longitudinal arrays of four iridium oxide electrodes were used to obtain single-unit recordings in supragranular, granular, and infragranular neurons in urethane anesthetized mice. The stimulation protocol consisted in a stimulation train of three air puffs ( $20 \mathrm{~ms}$ duration each) in which the time interval between the first and the third stimuli was fixed $(500 \mathrm{~ms})$ and the time interval between the first and the second stimuli changed (regular: $250 \mathrm{~ms}$; "accelerando": $375 \mathrm{~ms}$; or "decelerando" stimulation train: $125 \mathrm{~ms}$ interval). Cortical neurons adapted strongly their response to regular stimulation trains. Response adaptation was reduced when accelerando or decelerando stimulation trains were applied. This facilitation of the shifted stimulus was mediated by activation of NMDA receptors because the effect was blocked by AP5. The facilitation was not observed in thalamic nuclei. Facilitation increased during periods of EEG activation induced by systemic application of IGF-I, probably by activation of NMDA receptors, as well. We suggest that response adaptation is the outcome of an intrinsic cortical information processing aimed at contributing to improve the detection of "unexpected" stimuli that disturbed the rhythmic behavior of exploration.
\end{abstract}

Key words: barrel cortex; IGF-I; NMDA; response adaptation; stimulation pattern; whisker movements

\section{Significance Statement}

To detect objects, rodents scan the environment by rhythmic movements of whiskers at 4-12 $\mathrm{Hz}$, suggesting that this rhythmic behavior may facilitate stimulus detection. This rhythmic input in the somatosensory cortex will be disturbed when the animal touches an object. We study whether spike responses in the somatosensory cortex are sensitive to small changes in the timing of the rhythmic sensory input. We find that responses were facilitated when a modification of the stimulation interval was introduced in the stimulation sequence. This facilitation was mediated by activation of NMDA receptors and increased during periods of EEG activation induced by IGF-I application. We suggest that the detection mechanism of shifted stimulus may play a role in sensory processing. 


\section{Introduction}

Animals actively gather sensory information through self-generated movements. For example, eye movements are used to foveate interesting regions of visual space. Eye movements can determine the visual sensory input that falls on the retina. Active touch is also a common behavior to discern the shape, size, and texture of objects (Szwed et al., 2003; Kleinfeld et al., 2006; Diamond and Arabzadeh, 2013; Bale and Maravall, 2018).

In rodents, tactile discrimination during exploratory behaviors is based on repetitively and rapidly swept back and forth of whiskers (whisking) across objects or surfaces in repeated rhythmic movements at frequencies between 4 and $12 \mathrm{~Hz}$, scanning their surroundings to obtain tactile information about nearby objects (Carvell and Simons, 1990; Berg and Kleinfeld, 2003; Von Heimendahl et al., 2007; Jadhav et al., 2009). Whisking in free air induces spike trains in the somatosensory barrel cortex (BC; Curtis and Kleinfeld, 2009), which will be disturbed when the animal touches an object (for review, see Kleinfeld and Deschênes, 2011). In addition, spike trains suffer a reduction of the response with time in a process termed as response adaptation. The functional role of the response adaptation process may be to alter the sensitivity of neurons to encode more efficiently sensory stimuli (Sharpee et al., 2006; Maravall et al., 2007, 2013; Ganmor et al., 2010) or to improve the detectability of rare stimuli by decreasing responses to frequent stimuli (Dragoi et al., 2002; Ulanovsky et al., 2003). It is established that neuronal responses in the $\mathrm{BC}$ adapt robustly to repetitive whisker stimulation (Ahissar et al., 2000, 2001; Chung et al., 2002; Khatri et al., 2009; Martin-Cortecero and Nuñez, 2014). However, response adaptation during whisking may be altered when a change in the interval between stimuli occurs, for example when whiskers touch an object.

The effect of the temporal pattern in a spike train has been studied by Segundo and colleagues (Perkel et al., 1963; Segundo et al., 1963; Villa et al., 2007). Stimulation with triplets in Aplysia ganglia showed that neuronal responses were sensitive to the timing of the stimulation pattern (Segundo et al., 1963). These findings suggest that a train of spikes induced, for example, by whisking

Received December 4, 2018; accepted March 8, 2019; First published March 22, 2019.

The authors declare no competing financial interests.

N.B.-Z., A.E.P.V., and A.N. designed research; N.B.-Z. and A.N. performed research; N.B.-Z., A.E.P.V., and A.N. analyzed data; N.B.-Z., A.E.P.V., and A.N. wrote the paper.

This work was supported by Grants from the Spanish Ministerio de Economía y Competitividad Grant (SAF2016-76462 AEI/FEDER, UE) and the Neuroheuristic Research Group. We thank Dr. Washington Buño for critical revision of this paper, Jose Manuel Ibarz for electronics support, and Marta Callejo for technical help.

Correspondence should be addressed to Angel Nuñez at Angel. nunez@uam.es.

https://doi.org/10.1523/ENEURO.0471-18.2019

Copyright (C) 2019 Barros-Zulaica et al.

This is an open-access article distributed under the terms of the Creative Commons Attribution 4.0 International license, which permits unrestricted use, distribution and reproduction in any medium provided that the original work is properly attributed. may contain information according to the temporal pattern of the sensory input. Our intention in this work is to determine whether spike responses in the BC are sensitive to small changes in the timing of the stimulation pattern (temporal jitter). We applied rhythmic whisker stimulation trains of three stimuli at a mean frequency of 4 $\mathrm{Hz}$ in which all intervals were equal ("regular" stimulation pattern, 250 ms between stimuli) or varied in a ramp: "accelerando" (intervals decreased, 375 + $125 \mathrm{~ms}$ ) or "decelerando" (intervals increased, $125+375 \mathrm{~ms}$ ). These stimulation patters try to mimic the sensory input when a whisker touches an object during whisking. Sensitivity to stimulation patterns has a general interest because it contributes to understand how the somatosensory system handles complex temporal information.

\section{Materials and Methods}

\section{Animals}

The experiments were performed on 24 adult C57BI/6J mice (25-30 g weight) of either sex. Mice were group housed with a $12 \mathrm{~h}$ light/dark cycle and had ad libitum to food and water. In accordance with European Community Council Directive 2010/63/UE all animal procedures were approved by the Ethical Committee of the Universidad Autónoma de Madrid (CEI72-1286-A156). Efforts were made to minimize animal suffering as well as to reduce the number of animals used.

\section{Electrophysiological recordings}

General anesthesia was induced by peritoneal injection of urethane (1.2 g/ $\mathrm{kg}$, i.p.). Depth of anesthesia was sufficient to eliminate pinch withdrawal, palpebral reflex and whisker movement and was assessed periodically throughout the surgical procedure and during electrophysiological recordings. Animals were placed in a Kopf small-animal stereotaxic device (David Kopf Instruments) in which surgical procedures and recordings were performed. The body temperature was maintained at $37^{\circ} \mathrm{C}$. An incision was made exposing the skull and a small hole was drilled in the bone in the skull overlying the whisker barrel field of the somatosensory $\mathrm{BC}(\mathrm{A}: 0-2 \mathrm{~mm}, \mathrm{~L}: 3-4$ $\mathrm{mm}$ from bregma and $\mathrm{V}: 0.3-1.1 \mu \mathrm{m}$ from the dura mater; Paxinos and Franklin, 2003). Longitudinal arrays of four Iridium oxide electrodes (15 $\mu \mathrm{m}$ electrode diameter; 200 $\mu \mathrm{m}$ separation between electrodes; 1-2 $\mathrm{M} \Omega$ impedance; Q1x4-5mm-200-177-Q4) manufactured by NeuroNexus Technologies were used to obtain single-unit recordings in the BC. The array was carefully advanced perpendicular to the cortical surface, using a remote-controlled micromanipulator (David Kopf Instruments). Thus, the most superficial recording site was located at layer 2/3 (300 $\mu \mathrm{m}$ from the surface) and the deepest one was located at layer 6 (1100 $\mu \mathrm{m}$ from the surface; Fig. $1 A)$.

Extracellular signals were preamplified through a homemade preamplifier. The signals were further amplified and bandpass filtered between $300 \mathrm{~Hz}$ and $3 \mathrm{kHz}$ using an $\mathrm{AC}$ preamplifier (1902 isolated preamplifier; Cambridge Electronic Design), digitized at $10 \mathrm{kHz}$ (Power 1401, CED), and stored for off-line analysis. The recording session lasted for 4-5 $\mathrm{h}$ after the beginning of the recording procedure. 
A

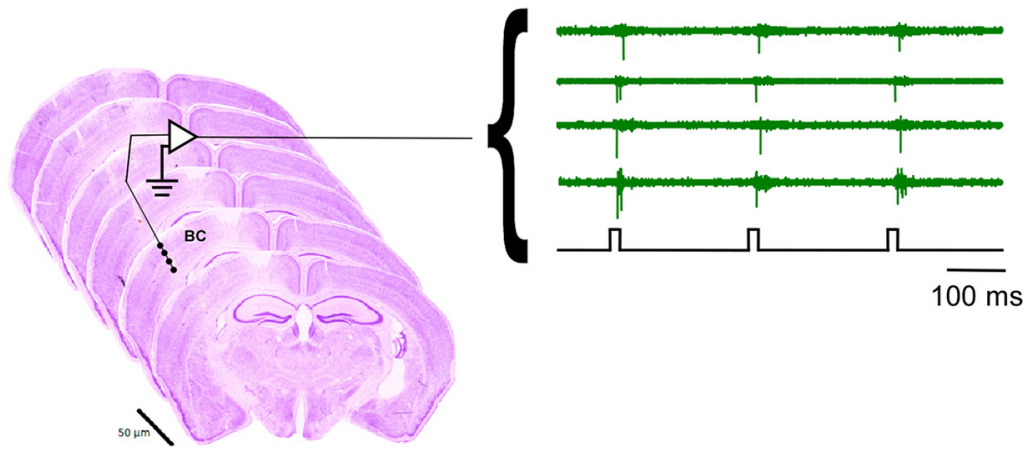

B
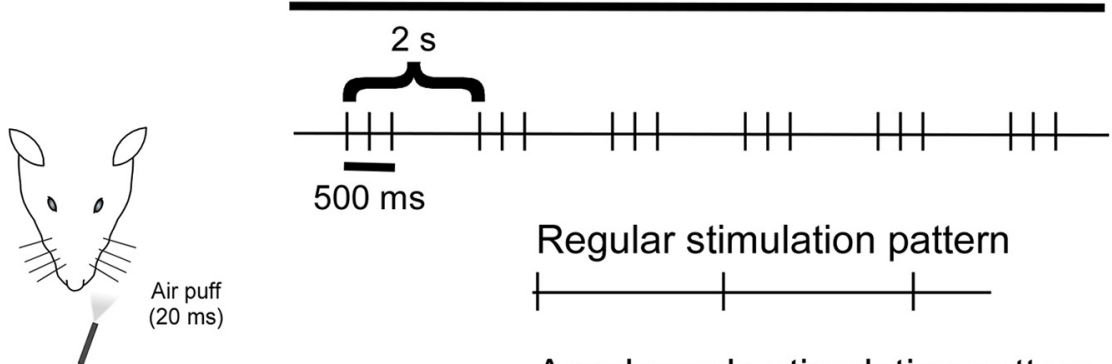

Regular stimulation pattern

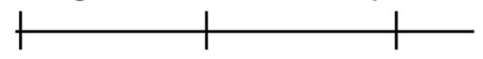

Accelerando stimulation pattern

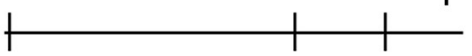

Decelerando stimulation pattern

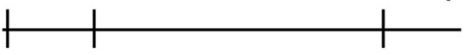

C

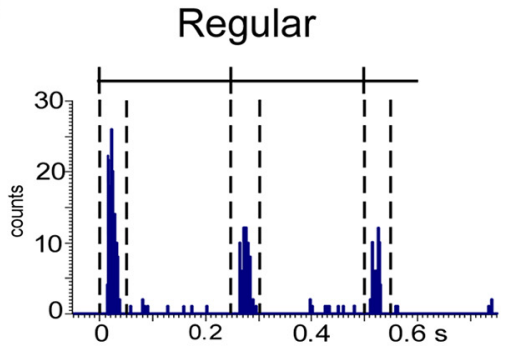

Accelerando

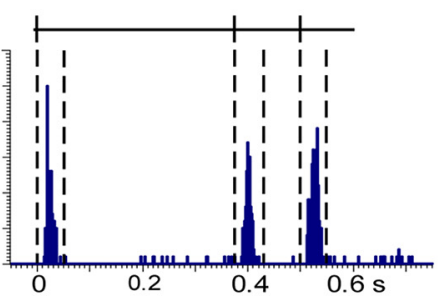

\section{Decelerando}

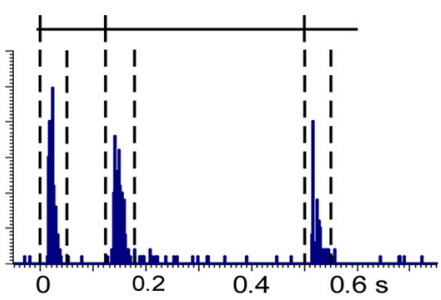

Figure 1. Response adaptation is altered by a change in the stimulation pattern. $\boldsymbol{A}$, Serial brain slices of a representative case in which the electrode track is observed. An example of spike responses is shown on the right (bottom recording represent stimuli). $\boldsymbol{B}$, A schematic diagram of the experimental protocol and stimulation patterns. $\boldsymbol{C}$, Representative PSTHs of a single unit located in layer 5 show response adaptation when a regular stimulation pattern is applied (left PSTH). Response adaptation is reduced if the interval between the first and the second stimuli increases from 250 to 375 ms (accelerando stimulation pattern; middle PSTH) or decreases to $125 \mathrm{~ms}$ (decelerando stimulation pattern; right PSTH). Lines on the PSTHs show the stimulation pattern. Vertical dashes lines indicate 50 ms poststimulus time window in which spike responses are calculated.

Figure Contributions: Natali Barros-Zulaica performed the experiments. All authors analyzed the data.

\section{Whisker stimulation}

For each recording, the principal whisker was determined as the whisker that caused the strongest response to manual mechanical deflection. All selected neurons responded to passive whisker deflections using a hand-held probe or air-puff stimuli generated by a pneumatic pressure pump (Picospritzer). After identification of the receptive field with the handheld probe, air-puff stimulation was delivered by aiming a $1 \mathrm{~mm}$ inner diameter polyethylene tube $10-20 \mathrm{~mm}$ away from the receptive field so that whiskers were pushed backward by a 20 ms duration puff (20-30 psi).

The stimulation protocol consisted in a stimulation train of three air puffs in which the time interval between the first and the third air puff was fixed $(500 \mathrm{~ms})$ and the time interval between the first and the second air puff changed (Fig. 1B):

- Regular stimulation pattern: the time interval between stimuli was $250 \mathrm{~ms}$. 
Table 1. Cortical responses to the whisker stimulation train (St. 1-3) according to the stimulation pattern (spikes/stimulus)

\begin{tabular}{|c|c|c|c|c|c|c|c|c|c|}
\hline \multirow[b]{2}{*}{ Layer } & \multicolumn{3}{|c|}{ Regular } & \multicolumn{3}{|c|}{ Accelerando } & \multicolumn{3}{|c|}{ Decelerando } \\
\hline & St. 1 & St. 2 & St. 3 & St. 1 & St. 2 & St. 3 & St. 1 & St. 2 & St. 3 \\
\hline Supragranular & $\begin{array}{l}1.37 \pm 0.26 \\
n=14\end{array}$ & $\begin{array}{l}0.89 \pm 0.18 \\
n=14\end{array}$ & $\begin{array}{l}0.69 \pm 0.1 \\
n=14\end{array}$ & $\begin{array}{l}1.26 \pm 0.20 \\
n=14\end{array}$ & $\begin{array}{l}1.17 \pm 0.23 \\
n=14\end{array}$ & $\begin{array}{l}1.07 \pm 0.29 \\
n=14\end{array}$ & $\begin{array}{l}1.56 \pm 0.20 \\
n=14\end{array}$ & $\begin{array}{l}1.55 \pm 0.26 \\
n=14\end{array}$ & $\begin{array}{l}1.12 \pm 0.15 \\
n=14\end{array}$ \\
\hline Granular & $\begin{array}{l}1.26 \pm 0.16 \\
n=12\end{array}$ & $\begin{array}{l}1.17 \pm 0.16 \\
n=12\end{array}$ & $\begin{array}{l}0.99 \pm 0.1 \\
n=12\end{array}$ & $\begin{array}{l}1.56 \pm 0.25 \\
n=12\end{array}$ & $\begin{array}{l}1.84 \pm 0.27 \\
n=12\end{array}$ & $\begin{array}{l}1.87 \pm 0.37 \\
n=12\end{array}$ & $\begin{array}{l}1.49 \pm 0.25 \\
n=12\end{array}$ & $\begin{array}{l}1.83 \pm 0.3 \\
n=12\end{array}$ & $\begin{array}{l}1.44 \pm 0.25 \\
n=12\end{array}$ \\
\hline Infragranular & $\begin{array}{l}1.88 \pm 0.29 \\
n=23\end{array}$ & $\begin{array}{l}1.33 \pm 0.13 \\
n=23\end{array}$ & $\begin{array}{l}1.18 \pm 0.1 \\
n=23\end{array}$ & $\begin{array}{l}1.77 \pm 0.19 \\
n=23\end{array}$ & $\begin{array}{l}1.66 \pm 0.19 \\
n=23\end{array}$ & $\begin{array}{l}1.73 \pm 0.25 \\
n=23\end{array}$ & $\begin{array}{l}1.94 \pm 0.18 \\
n=23\end{array}$ & $\begin{array}{l}1.81 \pm 0.2 \\
n=23\end{array}$ & $\begin{array}{l}1.42 \pm 0.17 \\
n=23\end{array}$ \\
\hline
\end{tabular}

- Accelerando stimulation pattern: the interval between the first and the second stimuli was $375 \mathrm{~ms}$ and thus, the second and the third stimuli were closer $(125 \mathrm{~ms})$.

- Decelerando stimulation pattern: the interval between the first and the second stimuli was $125 \mathrm{~ms}$ and thus, the second and the third stimuli were 375 ms faraway.

In all cases the mean frequency of the stimulation train was $4 \mathrm{~Hz}$ and was repeated 100 times at $0.5 \mathrm{~Hz}$ (stimulation block). These stimulation protocols tried to compare a regular stimulation pattern at $4 \mathrm{~Hz}$ with a stimulation pattern containing temporal jitter in the second stimuli. This pattern of stimulation is reminiscent of that produced by an object that interferes with the rhythmic movement of whiskers during the whisking behavior.

\section{Drugs}

The following drugs were used: 2-amino-5phosphonopentanoic acid (AP5; $50 \mu \mathrm{M}$ ), which is a selective NMDA (Sigma-Aldrich Quimica) receptor antagonist. AP5 was injected $(0.1 \mu l)$ through a cannula connected to a Hamilton syringe located $300 \mu \mathrm{m}$ deep in the BC to affect the entire cortical column. IGF-I $(1 \mu \mathrm{g} / \mathrm{g}$ body weight; Peprotech) was injected intraperitoneally to increase cortical excitability.

\section{Histology}

Following the recording session, electrolytic lesions were performed using five pulses of $5 \mu \mathrm{A}$ for $10 \mathrm{~s}$ at intervals of $10 \mathrm{~s}$ at the top and at the bottom of the electrode array for subsequent histologic reconstruction of the electrode tracks in coronal sections through the barrel cortex. At the end of the experiment the brain was processed for histology to corroborate the electrode track and electrode location. Animals were euthanized with an overdose of pentobarbital and perfused through the heart with $100 \mathrm{ml}$ of $0.9 \% \mathrm{NaCl}$, followed by $100 \mathrm{ml} 4 \%$ paraformaldehyde in $0.1 \mathrm{~m}$ phosphate buffer. Coronal sections $(50 \mu \mathrm{m})$ were obtained using a Leica freezing microtome and stained with cresyl violet (Fig. 1A).

\section{Statistical analysis}

One to two cells were detected from each single electrode based on the spike amplitude and wave form. Selected neurons showed a response to the stimulation of a whisker located in the contralateral pad. Only neurons that met this criterion were used for further analysis. According to their firing rate of the recorded neurons we assumed that all recorded neurons were pyramidal (see Results section). Spikes were digitally stored for time series analysis. All subsequent analysis was performed with Spike 2 software (Cambridge Electronic Design).

Spontaneous spike firing was calculated from periods of $120 \mathrm{~s}$ without whisker stimulation. Peristimulus time histograms (PSTHs) were calculated for cortical neurons, where time $0 \mathrm{~ms}$ of the histogram corresponded to the onset for the first stimulus in the stimulation train. Spike responses were calculated in a $50 \mathrm{~ms}$ poststimulus time window following each stimulus in the stimulation train (PSTH; 1 ms bin-width; 100 stimulation trains; Fig. 1C). The response for the first stimulus of the stimulation train was considered $100 \%$; the response for the second and the third stimuli was calculated with respect to this one. These response percentages were calculated in each neuron and the average and the SEM are indicated in the text and figures. Also, PSTHs were calculated for the first or for the last 25 stimulation trains of the 100 stimulation train block. Response duration was defined as the time elapsed from the onset to offset responses; response onset was defined as the first of three consecutive bins displaying significant activity $(2 \times$ higher than the mean firing rate) after stimulus and response offset as the last bin of the last three consecutive bins displaying significant activity. Response duration was measured for each stimulus into the stimulation train for each of the different stimulation patterns.

Statistical analysis was performed using GraphPad Prism 7 software. Statistical analyses consisted, for the most part, of paired comparisons of responses evoked in the same neuron by different stimulation trains or drugs. Data were considered normally distributed, according to the Shapiro-Wilk normality test, and thus, we used parametric statistics. We used the $t$ test (paired or independent) to compare data from two groups. The statistic test was applied on the values of response (spikes/stimulus; Table 1) in different conditions. Differences were considered statistically significant at the $95 \%$ level $(p<0.05)$. However, the normalized percentage respect to the first response in the stimulation train is shown in Figures and the statistical significant is indicated with asterisks. Data are presented as mean \pm SEM.

\section{Results}

To study the effect of different stimulation patterns in $B C$ responses we separated recorded cortical cells into three groups according to the cortical depth and observation of the histologic preparations (Fig. 1A): supragranular cells (up to $500 \mu \mathrm{m}$ below the pia; layers 2-3); granular cells between 500 and $800 \mu \mathrm{m}$ approximately represent- 
ing layer 4 cells and infragranular cells below $800 \mu \mathrm{m}$ (layers 5-6). Neurons recorded in the BC $(n=66)$ showed a low spontaneous firing rate as is characteristic of the urethane anesthetized mice (de Kock and Sakmann, 2009). Granular and supragranular neurons showed the lowest spontaneous firing rate $0.9 \pm 0.22$ spikes/s $(n=$ 16) and $1.0 \pm 0.22$ spikes/s $(n=16)$, respectively, whereas infragranular neurons showed higher firing rate, $1.7 \pm 0.18$ spikes/s $(n=34)$. The low spontaneous firing rate strongly suggests that these recordings could be performed in pyramidal dendrites because they have firing rates larger than somatic spike rates (Moore et al., 2017). Results are based on the analysis of BC neurons which responded to whisker stimulation of the contralateral pad. There were no gender-related differences in the results; for this reason, they were pooled together. Responses consisted in a short-latency spike-burst of 1-3 action potentials. Supragranular neurons showed $1.4 \pm 0.26$ spikes/stimulus $(n=16)$, granular neurons $1.3 \pm 0.16$ spikes/stimulus ( $n=16)$, and infragranular neurons $1.9 \pm$ 0.29 spikes/stimulus $(n=34)$, measured in a $50 \mathrm{~ms}$ poststimulus time window following the stimulus onset.

\section{The stimulation pattern altered response adaptation}

Cortical neurons adapted strongly their response to regular stimulation trains at $4 \mathrm{~Hz}$, as shown by the PSTHs. A representative example of a neuron located in layer 5 is shown in Figure $1 C$ (left histogram) in which the spike response decreased during the stimulus train. The population analysis indicated that adaptation was lower in the granular layer than in supragranular or infragranular layers (Table 1, regular stimulation pattern; Fig. 2, blue circles in all figures), consistent with other previous studies (Higley and Contreras, 2003; Khatri et al., 2004; Martin-Cortecero and Nuñez, 2014). The response adaptation was reduced if the interval between the first and the second stimulus increased from 250 to $375 \mathrm{~ms}$ (accelerando stimulation pattern; orange circles in all figures) or decreased to 125 ms (decelerando stimulation pattern; gray circles in all figures). Examples of these differences are depicted in Figure $1 C$, where PSTHs were calculated from a unit located in layer 5 when different stimulation patterns were applied. The response to the second and third stimuli of the stimulation train varied according to the interval between stimuli. Figure 2 shows population data measuring the mean percentage of the response respect to the control (first stimulus of the stimulation train; 100\%) for each cortical layer $(A-C$, supragranular, granular or infragranular layers, respectively); plots of responses to the 1-3 whisker stimuli are shown on the left. Differences between one and three stimulus responses during the application of the accelerando or decelerando stimulation pattern relative to the corresponding response during the application of a regular stimulation pattern are shown on the right. In all cases the response to the second and third stimuli was higher than during the application of the regular stimulation pattern, indicating that the adaptation observed in all layers during the application of the regular stimulation pattern was diminished when the interval between stimuli changed.
The response to the second and third stimuli in supragranular neurons $(n=14)$ was higher during the application of the accelerando stimulation pattern comparing to the regular stimulation pattern (28 and $35 \%$, respectively; $p=0.045$ and $p=0.0022$, respectively; paired $t$ test; Fig. $2 A$; Table 1) as well as during the application of the decelerando stimulation pattern (34 and 22\%, respectively; $p=0.0022$ and $p=0.0014$, respectively; paired $t$ test). Equally, this effect was observed in granular neurons $(n=12)$. Responses were higher during the application of the accelerando stimulation pattern (24 and $41 \%$, respectively; $p=0.0192$ and $p=0.0019$; paired $t$ test) or the decelerando stimulation pattern than it was expected during the application of the regular stimulation pattern (29 and 18\%, respectively; $p=0.0029$ and $p=0.019$; paired $t$ test; Fig. 2B; Table 1).

Neurons in infragranular layers also altered their response when a change of the interval between the first and the second stimuli occurred, especially during the application of the accelerando stimulation pattern. Layer 5 neurons $(n=23)$ showed a higher response during the application of the accelerando stimulation patter than it was expected during the application of the regular stimulation pattern ( 21 and $35 \%$, for the second and third stimuli of the train, respectively; $p=0.0103$ and $p=$ 0.0005 , respectively; paired $t$ test; Fig. $2 C$; Table 1). During the application of the decelerando stimulation pattern only the response to the second stimulus was higher than the response during the regular stimulation pattern $(20 \%$; $p=0.0181$; paired $t$ test; Fig. $2 C$; Table 1); the response to the third stimulus was not statistically different $(10 \% ; p>$ $0.05)$. In conclusion, the above results indicated that cortical cells are able to detect a change in the stimulation pattern, facilitating the detection of no-regular timing stimuli that appear into a rhythmic sequence of stimulation.

To establish whether this mechanism is proper of the cortex or appears in other subcortical relay stations of the somatosensory pathway we recorded multiunit activity in the ventro-posterior (VPM) or posterior-medial (POm) thalamic nuclei. VPM recordings showed that response adaptation was the same when VPM neurons were stimulated with the regular, accelerando or decelerando stimulation patterns $(n=12$; Fig. $3 A)$. The same occurred when POm thalamic neurons were recorded $(n=8$; Fig. $3 B$ ).

It is expected that the detection of the stimulus may change over time during the application of successive trains of stimuli. Above findings in the $\mathrm{BC}$ show the mean response after the application of a block of 100 stimulation trains. It is logical to believe that these findings are not the same during the long-lasting stimulation train. Figure 4 compares the response of the first with the last $25 \mathrm{stim}$ ulation trains during the application of the 100 stimulation trains with regular, accelerando or decelerando stimulation patterns. In all layers, response adaptation during the application of the regular stimulation pattern was larger during the first stimulation trains (red points) in comparison with the last stimulation trains (Fig. $4 A$, green points). Equally, the facilitation observed when the interval between the first and the second stimuli was longer, during 
A

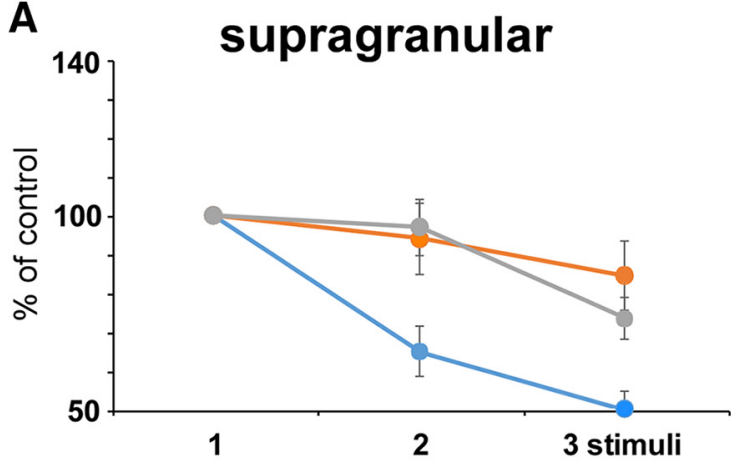

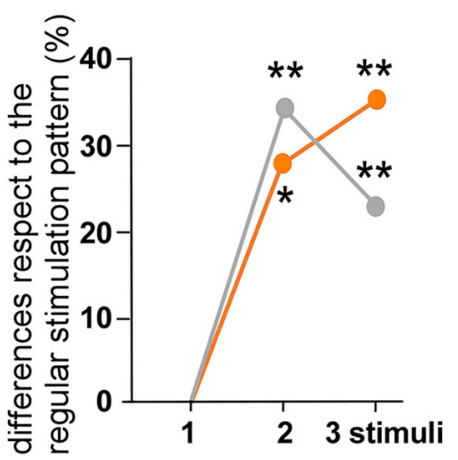
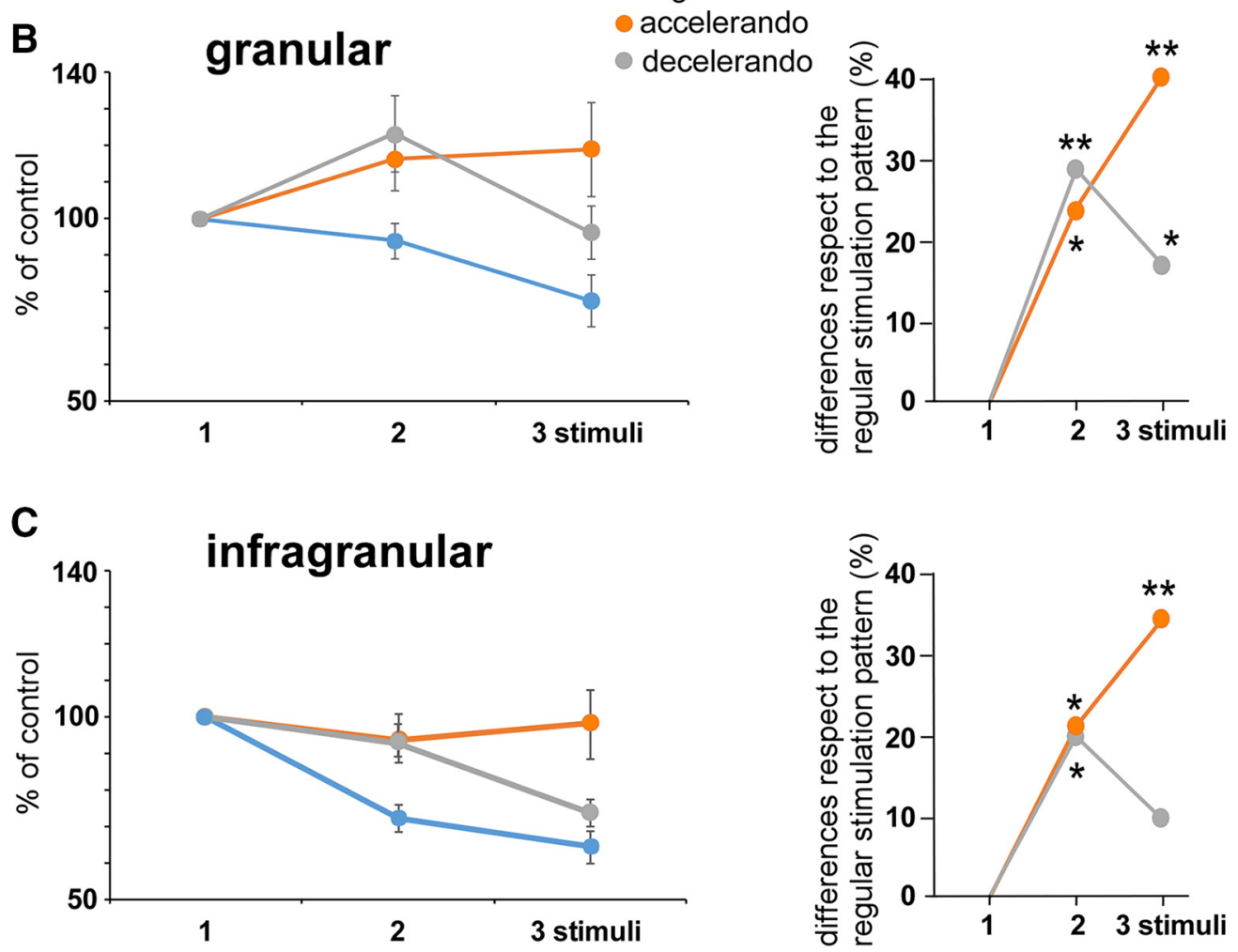

Figure 2. Response adaptation is altered by a change in the stimulation pattern. $\boldsymbol{A}$, Supragranular neurons $(n=14)$ show a reduction in spike response during the application of the regular stimulation pattern (three stimuli at $4 \mathrm{~Hz}$; blue circles). The mean percentage of the response respect to the control stimulus (first stimulus of the stimulation train) is shown on the left. The response adaptation is reduced if the interval between the first and the second stimuli increases from 250 to 375 ms (accelerando stimulation pattern; orange circle) or decreases to $125 \mathrm{~ms}$ (decelerando stimulation pattern; gray circle). The plots shown on the right display differences in the percentage of responses to the 1-3 stimuli during the application of the accelerando or decelerando stimulation patterns respect to the corresponding percentage to the 1-3 stimuli during the application of a regular stimulation pattern. In all cases the response to the second and third stimuli is higher than is expected during the regular stimulation pattern. $\boldsymbol{B}, \boldsymbol{C}$, Same plots as in $\boldsymbol{A}$ from granular $(n=12)$ and infragranular $(n=23)$ neurons, respectively. Equally, responses during the accelerando or decelerando stimulation pattern are greater respect to the corresponding response during the application of a regular stimulation pattern. $* p<0.05 ; * * p<0.01$.

Figure Contributions: Natali Barros-Zulaica performed the experiments. All authors analyzed the data.

the application of the accelerando stimulation pattern respect to the responses during the regular stimulation pattern, was also larger in granular and infragranular neurons (Fig. 4B). However, supragranular neurons showed facilitation respect to the responses observed during the application of the regular stimulation pattern between the second and the third stimuli for the first 25 stimulation trains which disappeared for the last stimulation trains.
During the application of the decelerando stimulation pattern the response facilitation observed between the first and the second stimuli was larger in all layers in the first stimulation trains than in the last stimulation trains (Fig. $4 C)$. Thus, facilitation processes evoked by a change in the interval between stimuli decayed during the stimulation period. The response adaptation was similar in the last stimulation trains during the application of the regular, 
A

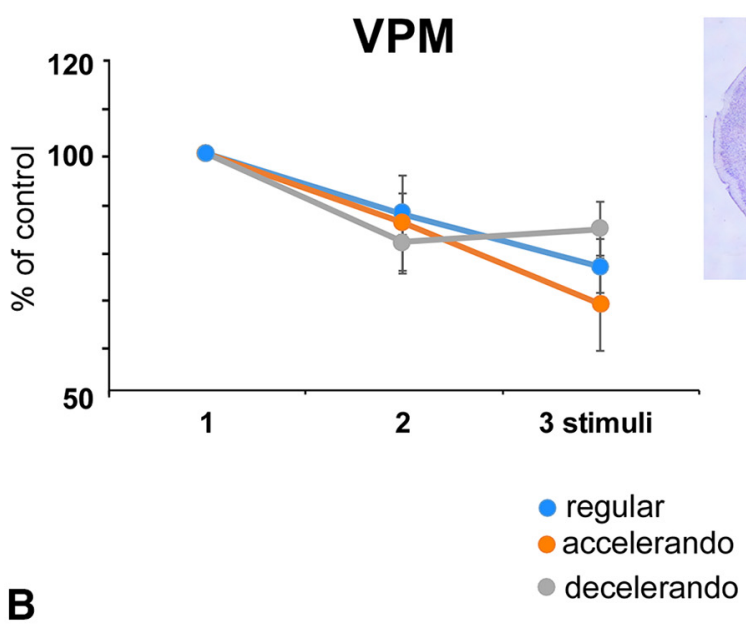

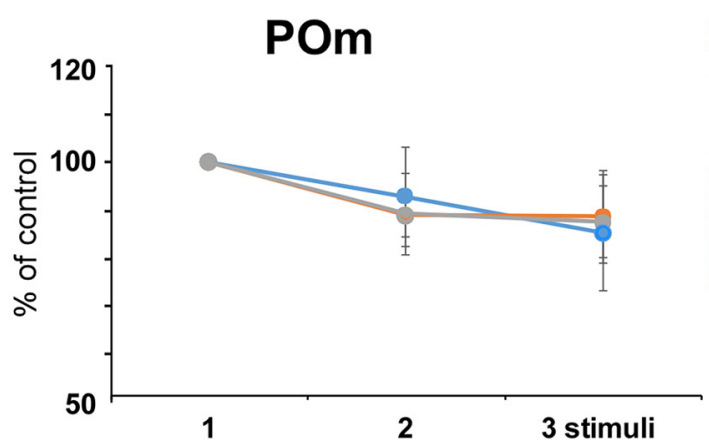
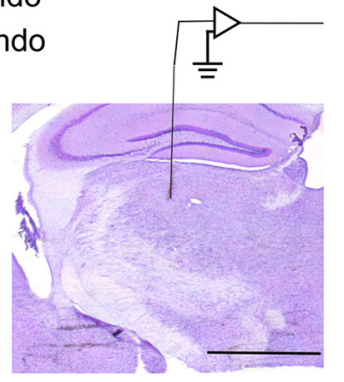

Figure 3. Response adaptation in thalamic neurons is not altered by the stimulation pattern. $\boldsymbol{A}$, The mean percentage of the response respect to the control stimulus (first stimulus of the stimulation train) is shown for VPM $(n=12)$. $\boldsymbol{B}$, Same plot that in A for POm $(n=8)$ neurons. Response adaptation is not altered by the stimulation pattern (regular, accelerando or decelerando stimulation patterns. Right, Brain slices of representative cases in which the electrode track is observed. Scale bars, $1 \mathrm{~mm}$.

Figure Contributions: Natali Barros-Zulaica performed the experiments. All authors analyzed the data.

accelerando or decelerando stimulation pattern for neurons of all layers.

\section{NMDA receptors are involved in the detection of a change in the stimulation pattern}

Above results indicated that response facilitation occurred when the interval between stimuli was reduced from 250 to $125 \mathrm{~ms}$. Paired-pulse facilitation is because of the activation of NMDA-mediated responses in many cortical regions (Thomson, 2000; Dan and Poo, 2004; Citri and Malenka, 2008). We have investigated the role of this glutamatergic receptor in the detection of the stimulation pattern by the application of the specific NMDA receptor blocker AP5 in the BC (Fig. 5A). Application of AP5 through a cannula located next to the recording microelectrode in the BC $(50 \mu \mathrm{M} ; 0.1 \mu \mathrm{l}$; recordings performed 10 min later) decreased tactile responses of supragranular neurons from $1.5 \pm 0.19$ to $0.7 \pm 0.09$ spikes/stimulus ( $p<0.001 ; n=8$; paired $t$ test) and from $1.8 \pm 0.13$ to 1.1 \pm 0.09 spikes/stimulus ( $p=0.005 ; n=8$; paired $t$ test) in infragranular neurons. However, granular neurons were not significantly affected (from $1.5 \pm 0.21$ to $1.2 \pm 0.10$ spikes/stimulus; $p>0.05 ; n=7$; paired $t$ test; Fig. $5 B$ ). A representative example is shown in the PSTHs of Figure
$5 A$. AP5 reduced whisker responses, decreasing response duration (see Fig. 7C).

Supragranular $(n=8)$ and infragranular $(n=8)$ neurons showed response adaptation during the application of the regular stimulation pattern 10 min after AP5 application (Fig. 5C, blue circles). They also adapted in presence of AP5 when the accelerando or decelerando stimulation pattern was applied (Fig. 5C, orange or gray circles, respectively); facilitation of the second and the third response was not observed, indicating that response facilitation described above elicited by a change in the interval between stimuli was because of the activation of NMDA receptors. Granular neurons also showed response adaptation during the application of the regular and decelerando stimulation patterns after AP5 application. However, a significant reduction of adaptation was observed during the application of the accelerando stimulation pattern in presence of AP5 $p=0.0325 ; n=7$; paired $t$ test; Fig. $5 C$, orange circles), suggesting that other mechanisms may be involved.

In a previous work we have demonstrated that an increase of NMDA-mediated response induces an increase in response duration of the BC neurons (Barros-Zulaica et al., 2014). Thus, we measured the response duration for 
A
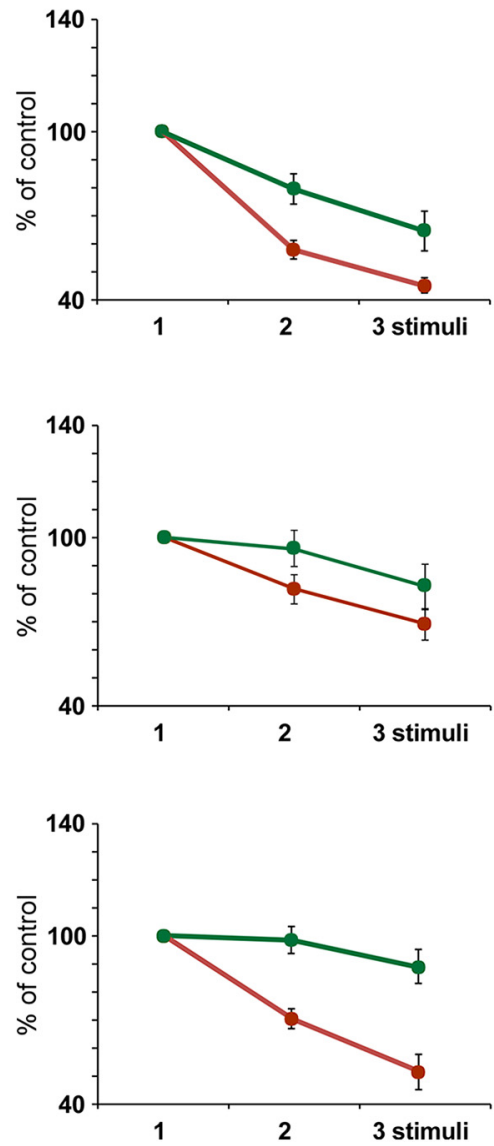

B

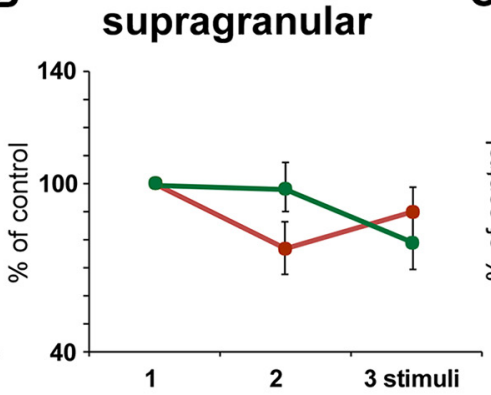

C

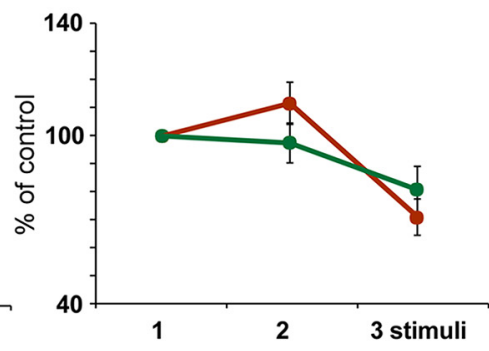

granular
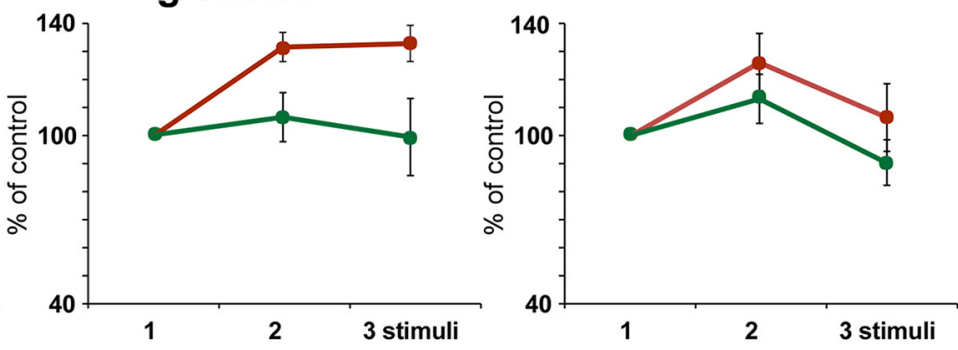

infragranular
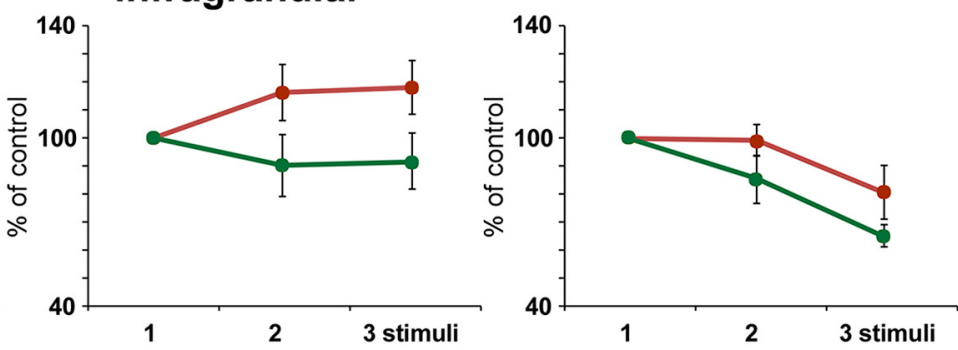

Figure 4. Response adaptation is altered during the stimulation period. Plots of the mean percentage of the response respect to the control stimulus (first stimulus of the stimulation train; $100 \%$ ) are shown. Data are calculated from PSTHs calculated with the first 25 stimulation trains (red) or with the last 25 stimulation trains (green) of the 100 stimulation train block applied to BC neurons. $\boldsymbol{A}$, Response adaptation during the application of the regular stimulation pattern is larger in the first 25 stimulation trains for supragranular ( $n=14$; top plots), granular ( $n=12$; middle plots), and infragranular ( $n=23$; bottom plots) neurons. $\boldsymbol{B}, \boldsymbol{C}$, Same plots that in $\boldsymbol{A}$ for neurons recorded during the application of accelerando or decelerando stimulation patterns, respectively. In all cases the response to the second and third stimuli is higher in the first stimulation trains than in the last stimulation train of the stimulation block.

Figure Contributions: Natali Barros-Zulaica performed the experiments. All authors analyzed the data.

each stimulus into the stimulation train during the application of different stimulation patterns (see Materials and Methods) to further study the participation of NMDA receptors in the detection of the stimulation pattern. The response duration of granular cells $(27.0 \pm 1.2 \mathrm{~ms})$ was significantly shorter than responses in supragranular (31.8 $\pm 1.5 \mathrm{~ms} ; p=0.0211 ; t$ test) and infragranular neurons $(31.1 \pm 1.0 \mathrm{~ms} ; p=0.0151 ; t$ test) when the response duration was measured in the first stimulus of the stimulation train. Figure $6 A$ shows the mean response duration of neurons located in supragranular $(n=11)$, granular $(n=$ $11)$, and infragranular layers $(n=16)$ during the application of the regular, accelerando or decelerando stimulation patterns (Table 2). When the interval between stimuli was reduced to $125 \mathrm{~ms}$ (between the second and the third stimuli in the accelerando stimulation pattern or between the first and the second stimuli in the decelerando stimulation pattern) the duration increased in the second one, reaching statistical significance in supragranular and infra- granular neurons. Granular neurons only showed significant differences during the application of the accelerando stimulation pattern. These findings support that the response facilitation observed during the application of the accelerando or decelerando stimulation pattern was mainly because of activation of NMDA receptors. Accordingly, the application of AP5 into the BC $(50 \mu \mathrm{M} ; 0.1 \mu \mathrm{l})$ reduced the duration of whisker responses in supragranular (from 30.5 \pm 1.3 to $25.6 \pm 0.7 \mathrm{~ms} ; n=8 ; p=0.0012$; paired $t$ test) and in infragranular neurons (from $32.3 \pm 1.3$ to $25.3 \pm$ $0.5 \mathrm{~ms} ; n=8 ; p<0.001$; paired $t$ test). Granular neurons slightly decreased their response duration but did not reach statistical significance (from $26.5 \pm 1.5$ to $23.9 \pm$ $0.7 \mathrm{~ms} ; n=7 ; p>0.05$; paired $t$ test). Furthermore, response duration was not altered by the stimulation pattern in presence of AP5 (Fig. 6B). These findings matched above results obtained when spike responses were measured (Fig. 5), indicating that shortening the interval between stimuli in a stimulation train generated a response 
A

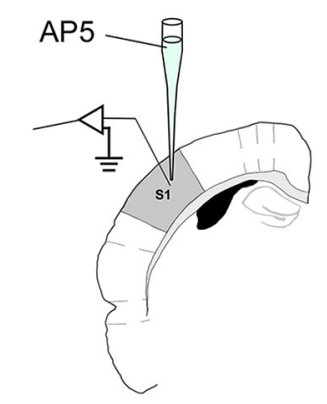

B
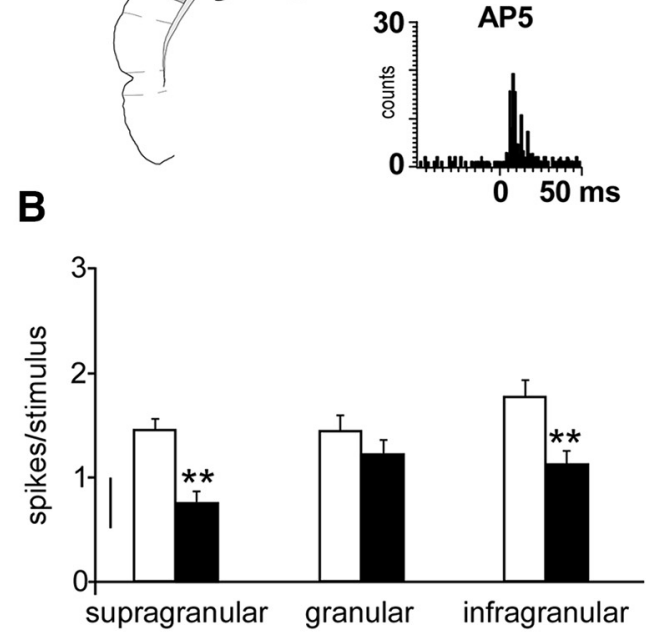
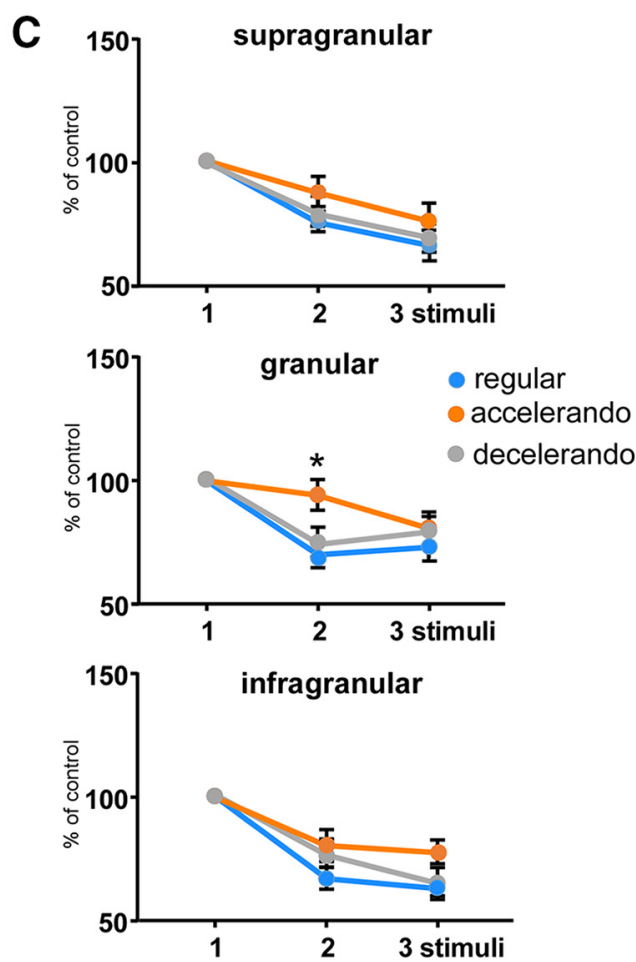

Figure 5. Changes in the response adaptation induced by the stimulation pattern are because of activation of NMDA receptors. $\boldsymbol{A}$, Schematic diagram of the experimental protocol. Insets, PSTHs of the response of layer 5 neurons in the control condition and 10 min after AP5 application (50 $\mu \mathrm{M}, 0.1 \mu \mathrm{l}$; black bars); the response is clearly reduced. $\boldsymbol{B}$, Responses to whisker stimuli are reduced after cortical injection of AP5 (50 $\mu \mathrm{M}, 0.1 \mu \mathrm{l}$; black bars) respect to control values (white bars) in supragranular $(n=8)$, granular $(n=7)$, and infragranular $(n=8)$ neurons. $\boldsymbol{C}$, Mean percentage of the response respect to the control stimulus (first stimulus of the stimulation train) is shown. Supragranular and infragranular neurons adapt equally in presence of AP5 when the regular, accelerando, or decelerando stimulation patterns are applied. Granular neurons also show response adaptation during the application of the regular and decelerando stimulation patterns after AP5 application. However, a significant reduction of adaptation is observed during the application of the accelerando stimulation pattern. $* p<0.05 ; * * p<0.01$.

Figure Contributions: Angel Nuñez performed the experiments. All authors analyzed the data.

facilitation that was mediated by the activation of NMDA receptors.

\section{IGF-I facilitates stimulus detection}

Above results have been obtained under urethane anesthesia, a state characterized by the prevalence of synchronous slow oscillations (Steriade, 1993; Castro-Alamancos and Bezdudnaya, 2015). However, natural active whisking occurs in aroused animals exploring the environment; a state characterized by the absence of slow oscillations (cortical activation). It has been demonstrated that systemic application of IGF-I increases neuronal firing (Carro et al., 2000; Nuñez et al., 2003; Mysoet et al., 2015) and activates the electroencephalogram (Trueba-Sáiz et al., 2013). Thus, IGF-I was injected intraperitoneally to study whisker responses and the stimulation pattern effect during a state of increased cortical activation such as occurs during anesthesia. We performed simultaneous unit and field potential recordings in the BC of urethane anesthetized mice $(n=8)$ in control conditions (after injection of $0.1 \mathrm{ml}$ of saline solution, i.p.) and 20 minutes after intraperitoneal injection of IGF-I ( $1 \mu \mathrm{g} / \mathrm{g}$ body weight dissolved in $0.1 \mathrm{ml}$ of saline solution). Field potentials were recorded to determine that IGF-I induced cortical activation. In control conditions, field potentials showed slow waves evoked by the anesthetic (Fig. 7A, control). Intraperitoneal administration of IGF-I elicited an increase of the firing rate and a reduction of the slow wave amplitude in the cortex (Fig. 7A, IGF-I). This effect was accompanied with an increase in the response to whisker stimulation in neurons located in all cortical layers (Fig. 7B, closed bars). Supragranular neurons increased whisker responses from $1.4 \pm 0.08$ spikes/stimulus in control condition $(n=6)$ to $2.5 \pm 0.35$ spikes/stimulus 20 min after IGF-I intraperitoneal injection ( $p=0.0128 ; n=6$; paired $t$ test). Similarly, granular neurons increased whisker responses from $1.6 \pm$ 0.16 spikes/stimulus in control condition to $2.2 \pm 0.24$ spikes/stimulus ( $p=0.0293 ; n=6$; paired $t$ test) and infragranular neurons increased whisker responses from $1.8 \pm 0.22$ spikes/stimulus in control condition to $2.7 \pm$ 0.2 spikes/stimulus after IGF-I injection ( $p=0.0049 ; n=$ 9; paired $t$ test). The evoked facilitation by IGF-I of whisker responses was blocked if AP5 $(50 \mu \mathrm{M} ; 0.1 \mu \mathrm{l})$ was injected in the BC 10 min before IGF-I injections (Fig. 6B, green bars). In this condition, supragranular neurons showed 1.0 \pm 0.3 spikes/stimulus $(p>0.05$, respect to control values; $n=4$; paired $t$ test), granular neurons showed $1.2 \pm 0.29$ spikes/stimulus ( $p>0.05 ; n=4$; paired $t$ test) and infragranular neurons showed $1.2 \pm 0.38$ spikes/stimulus after IGF-I injection ( $p>0.05 ; n=5$; paired $t$ test). 
A
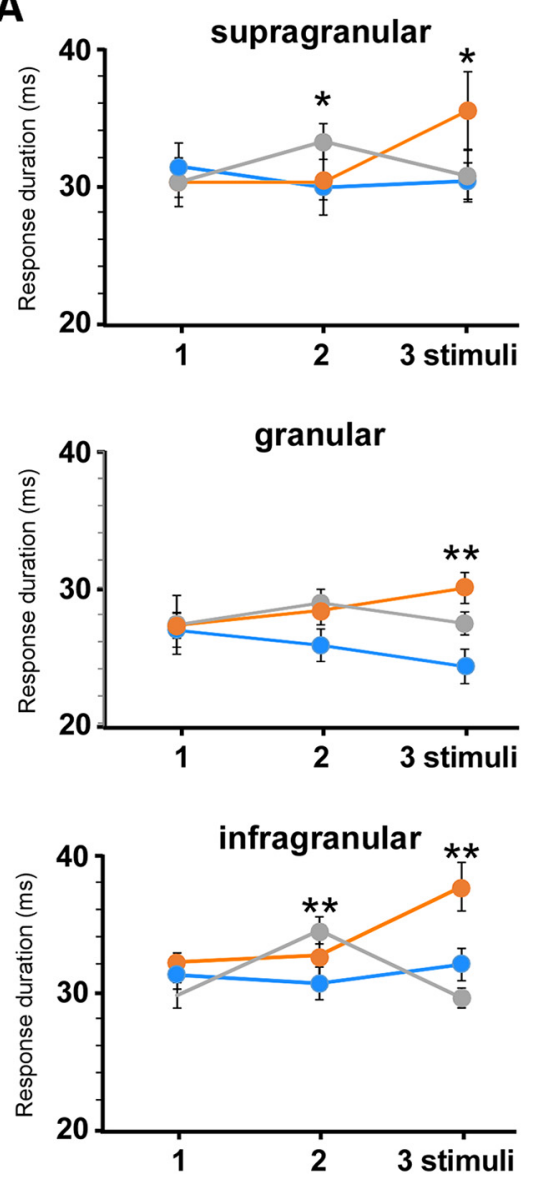

B

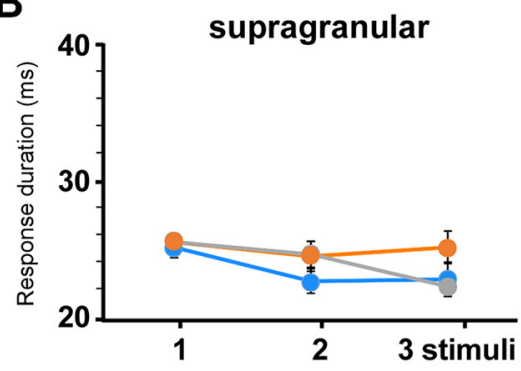

- regular - accelerando

- decelerando
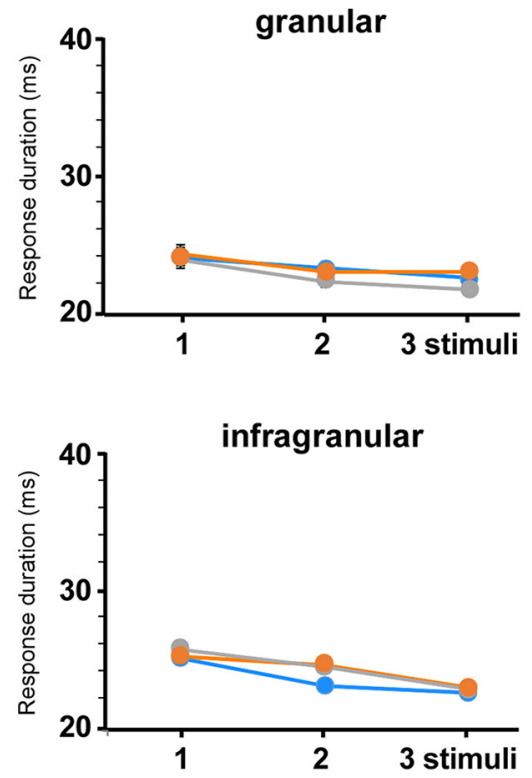

Figure 6. The stimulation pattern also induces changes in the whisker response duration. $\boldsymbol{A}$, Response duration according to the stimulation pattern in each cortical layer. $\boldsymbol{B}$, Application of AP5 into the BC $(50 \mu \mathrm{m} ; 0.1 \mu \mathrm{l})$ reduces the duration of whisker responses and blocks the effect of the stimulation pattern. $* p<0.05 ; * * p<0.01$.

Figure Contributions: Natali Barros-Zulaica and Angel Nuñez performed the experiments. All authors analyzed the data.

Consequently, the increased whisker response evoked by IGF-I may be because of activation of NMDA receptors.

As it was expected, IGF-I injection also induced an increase of the response duration (Fig. 7C, closed bars). Supragranular neurons increased response duration from $29.2 \pm 1.08 \mathrm{~ms}$ in control condition $(n=6)$ to $34.5 \pm 1.3$ ms 20 min after IGF-I intraperiotneal injection $(p=0.0128$; $n=6$; paired $t$ test). Similarly, granular neurons increased whisker response from $26.5 \pm 0.68 \mathrm{~ms}$ in control condition to $29.0 \pm 1.21 \mathrm{~ms}$ ( $p=0.0278 ; n=6$; paired $t$ test) and infragranular neurons increased whisker response from $29.5 \pm 2.02$ to $35.2 \pm 2.15 \mathrm{~ms}$ after IGF-I injection (p
$<0.001 ; n=9$; paired $t$ test). Similarly, the increase in the response duration evoked by IGF-I was blocked if AP5 (50 $\mu \mathrm{M} ; 0.1 \mu \mathrm{l})$ was injected in the $\mathrm{BC} 10 \mathrm{~min}$ before IGF-I injections (Fig. 7C, green bars). In this condition, supragranular neurons showed a response duration after IGF-I injection of $25.3 \pm 1.44 \mathrm{~ms}(p>0.05$, respect to control values; $n=4$; paired $t$ test), granular neurons showed $26.5 \pm 0.58 \mathrm{~ms}(p>0.05 ; n=4$; paired $t$ test $)$ and infragranular neurons showed $24.6 \pm 2.22$ ms after IGF-I injection ( $p>0.05$; $n=5$; paired $t$ test).

In addition, response adaptation to the regular stimulation pattern was reduced and the facilitation of responses

Table 2. Duration of cortical responses to whisker stimulation trains of three stimuli (St. 1-3), according to the stimulation pattern (in ms)

\begin{tabular}{|c|c|c|c|c|c|c|c|c|c|}
\hline \multirow{3}{*}{$\begin{array}{l}\text { Layer } \\
\text { oragranular }\end{array}$} & \multicolumn{3}{|c|}{ Regular } & \multicolumn{3}{|c|}{ Accelerando } & \multicolumn{3}{|c|}{ Decelerando } \\
\hline & St. 1 & St. 2 & St.3 & St. 1 & St. 2 & St. 3 & St. 1 & St. 2 & St. 3 \\
\hline & $\begin{array}{l}31.8 \pm 1.5 \\
n=11\end{array}$ & $\begin{array}{l}29.8 \pm 0.9 \\
n=11\end{array}$ & $\begin{array}{l}30.3 \pm 1.3 \\
n=11\end{array}$ & $\begin{array}{l}30.2 \pm 1.8 \\
n=11\end{array}$ & $\begin{array}{l}30.2 \pm 2.4 \\
n=11\end{array}$ & $\begin{array}{l}35.5 \pm 2.9 \\
n=11\end{array}$ & $\begin{array}{l}30.2 \pm 1.1 \\
n=11\end{array}$ & $\begin{array}{l}33.2 \pm 1.3 \\
n=11\end{array}$ & $\begin{array}{l}30.6 \pm 1.9 \\
n=11\end{array}$ \\
\hline Granular & $\begin{array}{l}27.0 \pm 1.2 \\
n=11\end{array}$ & $\begin{array}{l}25.9 \pm 1.3 \\
n=11\end{array}$ & $\begin{array}{l}24.4 \pm 1.3 \\
n=11\end{array}$ & $\begin{array}{l}27.4 \pm 0.9 \\
n=11\end{array}$ & $\begin{array}{l}28.5 \pm 1.1 \\
n=11\end{array}$ & $\begin{array}{l}30.1 \pm 1.1 \\
n=11\end{array}$ & $\begin{array}{l}27.4 \pm 2.1 \\
n=11\end{array}$ & $\begin{array}{l}29.0 \pm 1.0 \\
n=11\end{array}$ & $\begin{array}{l}27.5 \pm 0.8 \\
n=11\end{array}$ \\
\hline Infragranular & $\begin{array}{l}31.1 \pm 1.0 \\
n=16\end{array}$ & $\begin{array}{l}30.3 \pm 1.3 \\
n=16\end{array}$ & $\begin{array}{l}31.7 \pm 1.3 \\
n=16\end{array}$ & $\begin{array}{l}31.9 \pm 0.7 \\
n=16\end{array}$ & $\begin{array}{l}32.4 \pm 1.6 \\
n=16\end{array}$ & $\begin{array}{l}37.4 \pm 1.8 \\
n=16\end{array}$ & $\begin{array}{l}29.4 \pm 0.9 \\
n=16\end{array}$ & $\begin{array}{l}34.2 \pm 1.0 \\
n=16\end{array}$ & $\begin{array}{l}29.2 \pm 0.7 \\
n=16\end{array}$ \\
\hline
\end{tabular}


A

control

IGF-I
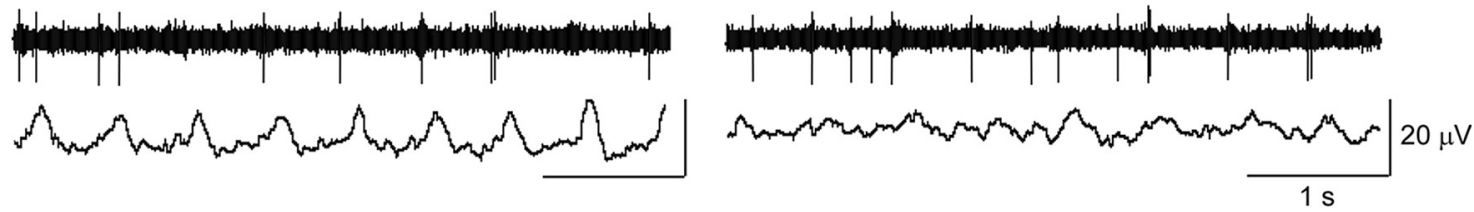

B

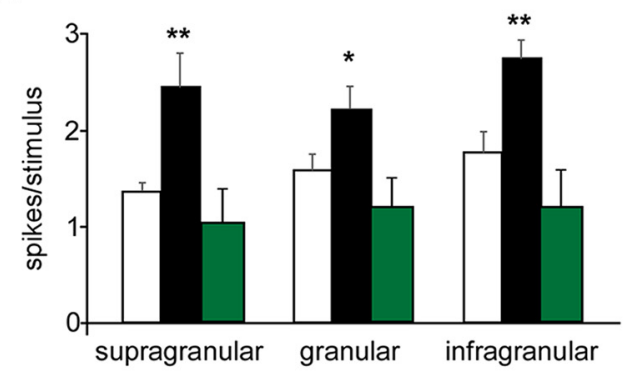

D
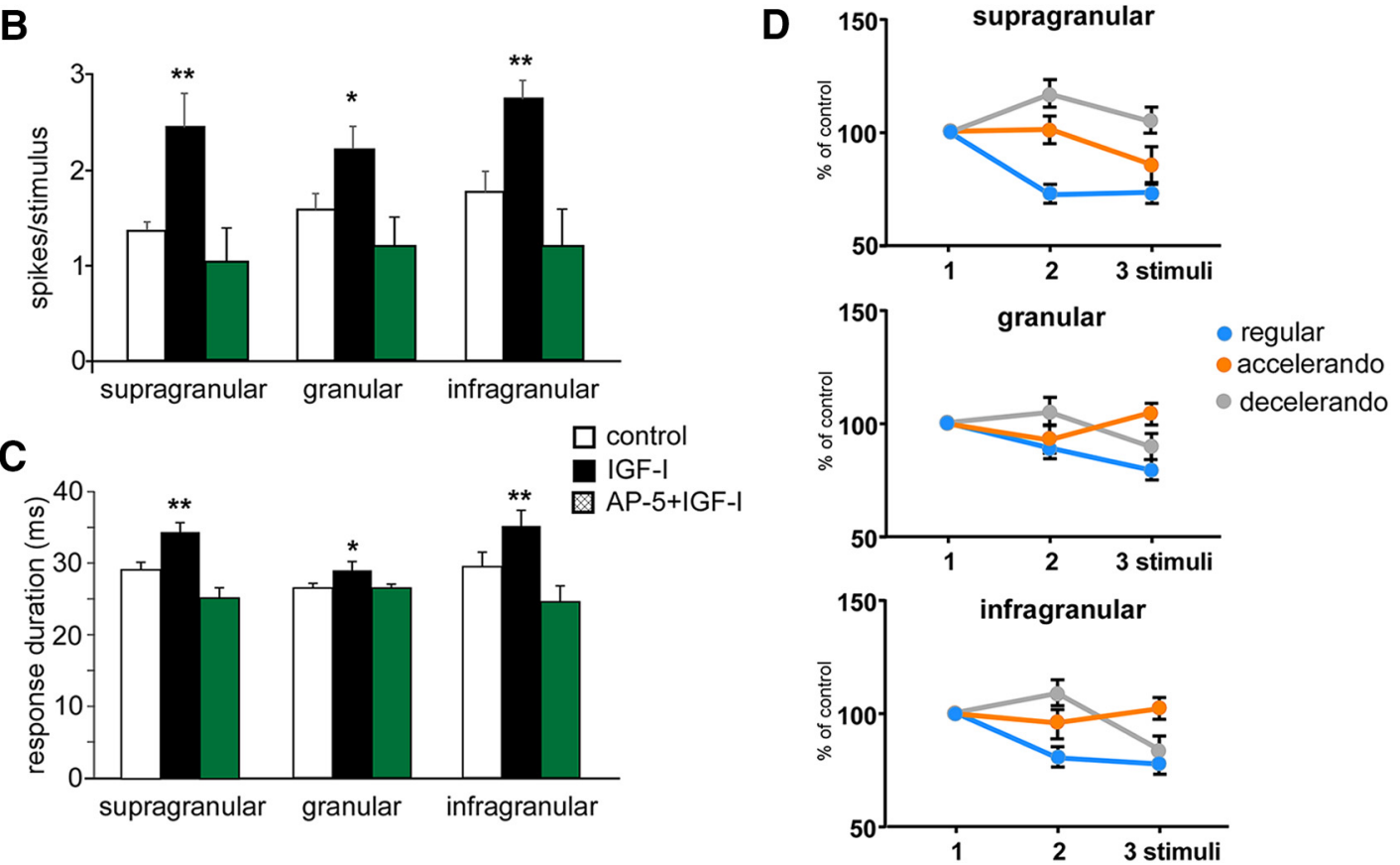

Figure 7. Changes in the response adaptation induced by the stimulation pattern are also observed during periods of EEG activation. $\boldsymbol{A}$, Unit and field potential activities (top and bottom traces, respectively) are shown in a representative case recorded in the supragranular layer. Intraperitoneal injection of IGF-I ( $1 \mu \mathrm{g} / \mathrm{g}$ body weight) induced a reduction of slow waves and an increase in the spontaneous firing rate. $\boldsymbol{B}$, Responses to whisker stimuli are increased after IGF-I intraperitoneal injection (closed bars) respect to control values (white bars) in supragranular $(n=6)$, granular $(n=7)$, and infragranular $(n=9)$ neurons. Facilitation by IGF-I of whisker responses is blocked after AP5 (50 $\mu \mathrm{m} ; 0.1 \mu \mathrm{l}$ ) injection in the BC (green bars). $\boldsymbol{C}$, IGF-I injection also induces an increase of the response duration (closed bars). Similarly, the increase in the response duration evoked by IGF-I is blocked if AP5 (50 $\mu \mathrm{M}$; $0.1 \mu \mathrm{l}$ ) is injected previously (green bars). $\boldsymbol{D}$, Mean percentage of the response respect to the control stimulus (first stimulus of the stimulation train) is shown. Response adaptation to the regular stimulation pattern is reduced and the facilitation of responses during the application of the accelerando or decelerando stimulation patterns are enhanced in supragranular, granular and infragranular layers after IGF-I administration. $* p<0.05 ; * * p<0.01$.

Figure Contributions: Angel Nuñez performed the experiments. All authors analyzed the data.

during the application of the accelerando or decelerando stimulation patterns was enhanced in all cortical layers after IGF-I administration (Fig. 7D), suggesting that response adaptation and detection of different timings were facilitated during a cortical activation state induced, in this case, by IGF-I.

\section{Discussion}

During exploration, rodents move their whiskers rhythmically across objects or surfaces (Carvell and Simons, 1990; Berg and Kleinfeld, 2003; Grant et al., 2009). This rhythmic behavior induces spike responses in $B C$ neurons that displayed a progressive adaptation with time (Derdikman et al., 2006; Katz et al., 2006). The rhythmic behavior to explore the environment is not exclusive of the somatosensory system or the whisker system, also appears in the visual or auditory systems and in different species, sug- gesting that it may facilitate the detection of stimuli (Szwed et al., 2003; Kleinfeld et al., 2006; Diamond and Arabzadeh, 2013). The effect of anesthesia on the adaptation, following the results reported for an oddball paradigm in anesthetized and freely-moving rats (Eriksson and Villa, 2005), suggests that response adaptation in unanesthetized animals is likely to be much larger than any observed modification during anesthesia. Our results show that response adaptation was reduced in BC layers when a modification of the stimulation interval was introduced in the stimulation sequence (shifted stimulus), decreasing (decelerando) or increasing (accelerando) the interval between the first and the second stimuli. The response to the shifted stimulus was greater than estimated during the $4 \mathrm{~Hz}$ regular stimulation. This facilitation was mediated by activation of NMDA receptors since the 
effect was blocked by AP5. Facilitation of the shifted stimulus increased during periods of EEG activation induced by IGF-I application, probably by activation of NMDA receptors because the increment of whisker responses induced by IGF-I was also blocked by AP5. This process may contribute to improve the detection of "unexpected" stimuli that disturbed the rhythmic behavior of exploration.

Adaptation, the reduction of the response to ongoing or repeated stimulation, occurs across species and sensory modalities (Ahissar et al., 2000; Maravall et al., 2007; Kheradpezhouh et al., 2017). The functional role of the response adaptation process may be to alter the sensitivity of neurons to encode sensory stimuli more efficiently (Sharpee et al., 2006; Maravall et al., 2007, 2013; Ganmor et al., 2010) or to improve the detectability of rare stimuli by decreasing responses to frequent stimuli (Dragoi et al., 2002; Ulanovsky et al., 2003). In the somatosensory system, most studies observed response depression in different layers of BC to whisker stimulation (Ahissar et al., 2000, 2001; Martin-Cortecero and Nuñez, 2014; Kheradpezhouh et al., 2017). We also observed a response depression when the regular stimulation pattern was applied. Our findings also showed that the introduction of a temporal jitter increased the response to the shifted stimuli in all cortical layers. An increased response to irregular stimulation has been previously described in the $\mathrm{BC}$, suggesting that may contribute to the detection of relevant stimuli (Lak et al., 2008; Kheradpezhouh et al., 2017).

Our findings showed that adaptation changed during the stimulation time. If we compared the response of the first stimulation trains with the last stimulation trains, we observed a reduction of adaptation with time, mainly in supragranular and infragranular layers (Fig. $4 A$ ). In addition, the response facilitation of the shifted stimulus was also reduced along the stimulation time (Fig. $4 B, C$ ), indicating that it may contribute to the detection of unexpected and non-repetitive stimuli.

During quiescent states the sensory adaptation observed in the neocortex is high and may be a consequence of depression at thalamocortical pathways; during activated states animals are alert exploring the environment; in this case sensory adaptation is reduced (CastroAlamancos, 2004). Results present here also showed a reduction of sensory adaptation during activated states (in this case induced by IGF-I injection; compare Figs. 2 and 7 during the application of the regular stimulation pattern). The reduction was more evident in supragranular and infragranular cells as was indicated early (Ahissar et al., 2001). Changes in sensitivity during adaptation may allow the neuronal circuit to respond optimally to a larger range of stimuli despite the limited dynamic range of neuronal firing (Derdikman et al., 2006; Katz et al., 2006). Synaptic mechanisms, such as enhancement of inhibition (Dealy and Tolhurst, 1974) or depression of excitatory synapses (Adorján et al., 1999; Ahissar et al., 2000; Sanchez-Vives and Mccormick, 2000; Chung et al., 2002; CastroAlamancos, 2004; Higley and Contreras, 2006; DíazQuesada and Maravall, 2008) have been proposed as mechanisms for adaptation. In vivo experiments have ruled out enhanced inhibition since iontophoretic application of $\mathrm{GABA}_{\mathrm{A}}$ receptor antagonists or agonists did not affect adaptation (Martin-Cortecero and Nuñez, 2014; Ayala and Malmierca, 2018). Derdikman et al. (2006) demonstrated that responses to frequent stimuli can depress, remain unchanged, or facilitate, depending on the information conveyed by the stimulus and the cortical layer. Here, a change in the interval between stimuli is enough to facilitate the response to the shifted stimulus. Thus, these results support the notion that cortical adaptation is not an automatic mechanism during repetitive stimulation but rather a process that depends and changes according to the sensory input pattern.

Recordings of thalamic cells showed a small adaptation during the application of a regular stimulation train, consistent with other previous studies conducted on VPM or POm neurons (Hellweg et al., 1977; Ahissar et al., 2000; Ahissar and Zacksenhouse, 2001; Sosnik et al., 2001; Hartings et al., 2003; Khatri et al., 2004; Martin-Cortecero and Nuñez, 2014). Moreover, either VPM or POm thalamic neurons were not sensitive to a change in the interval between stimuli, suggesting that this property is generated, at least in part, in the BC. Other brain structures may also contribute to the detection of relevant stimuli. For example, acetylcholine could enhance sensory detection, processing, and plasticity with the intervention of complex synaptic interactions (Ego-Stengel et al., 2001; CastroAlamancos, 2009; Rahman and Berger, 2011; Nuñez et al., 2012; Barros-Zulaica et al., 2014).

A likely mechanism for facilitation when the interval was shorter (125 ms) may be a paired-pulse facilitation mediated by the activation of NMDA receptors (Thomson, 2000; Dan and Poo, 2004; Citri and Malenka, 2008). Many long-term modifications in synaptic efficacy in the cortex have been proposed to be mediated by the activation of NMDA receptors and to be the cellular basis of the learning machinery and the detection of relevant stimuli (Nuñez et al., 2012; Nabavi et al., 2014; Gruart et al., 2015; Díez-García et al., 2017). For example, antagonists of NMDA receptors block cortical plasticity after electrical thalamic stimulation (Heynen and Bear, 2001) or whisker repetitive stimulation (Barros-Zulaica et al., 2014). Indeed, the facilitation observed during the accelerando or decelerando stimulation pattern of the shifted stimulus was blocked after cortical application of the NMDA receptor antagonist AP5 in supragranular and infragranular layers. However, this facilitation was not affected by AP5 in granular neurons during the application of the accelerando stimulation pattern, probably because of the different functional roles of each layer (Feldmeyer et al., 2013), in which different NMDA receptors subtypes are involved (Kaczmarek et al., 1997; Scheppach, 2016). Thus, the detection of an object that is interposed during the rhythmic whisker exploration may be facilitated by a mechanism that implies activation of NMDA receptors, mainly in supragranular and infragranular neurons. Granular cells express less this effect may be because they receive an important synaptic input from the thalamus, that is not sensitive to a change in the interval between stimuli, and 
faithfully follow the stimulation pattern, regardless of its temporal pattern.

A reduction of response adaptation to the second stimulus was also observed when the accelerando stimulation pattern was applied in comparison with the regular stimulation pattern. In this case, the interval between the first and the second stimuli was increased to $375 \mathrm{~ms}$ in which a facilitation mediated by NMDA receptors would be difficult to admit. However, this facilitation was also blocked by AP5 except in the case of granular cells. The increase of the interval between stimuli from 250 to $375 \mathrm{~ms}$ can increase the synaptic current available that can be activated by the second stimulus. In fact, previous studies have shown that at low stimulation frequencies BC neurons evoked greater responses than high stimulation frequencies (Ahissar et al., 2001; Ahissar and Zacksenhouse, 2001). In addition, membrane potential recordings of neurons in the somatosensory cortex showed that a sensory stimulus may induce depolarizations that lasted hundreds of milliseconds (Yamashita and Petersen, 2016). Thus, AP5 could reduce part of this synaptic current, blocking the facilitation observed during the application of the accelerando stimulation pattern in control conditions. Additional experiments are required to investigate the synaptic and network mechanisms responsible for this response facilitation.

It is known that systemic application of IGF-I increases neuronal firing (Carro et al., 2000; Nuñez et al., 2003; Mysoet et al., 2015) and induces EEG activation (Nishijima et al., 2010; Trueba-Sáiz et al., 2013). IGF-I is well known to be expressed throughout the brain, including the somatosensory cortex (Rotwein et al., 1988; Yamaguchi et al., 1990). Here, we show that IGF-I induced an increase in whisker responses by the activation of NMDA receptors because it was blocked by previous injection of AP5 in the BC. During the activation state evoked by IGF-I, BC neurons detected the change in the interval between stimuli, suggesting that the mechanism of detection of shifted stimulus may play a role in sensory processing during anesthesia, and also during activate states.

It is known that alterations of the rhythmic stimulation pattern induce important changes in the response (Perkel et al., 1963; Segundo et al., 1963; Villa et al., 2007), indicating that the discharge pattern of a train of spikes carries much more information than the simple mean discharge. Our results show that such higher-order information processing is likely to be primarily the outcome of an intrinsic cortical processing, built up on ascending thalamic input unaffected by stimulus dynamics. Consequently, the rhythmic exploration behavior observed in many sensory systems (Szwed et al., 2003; Kleinfeld et al., 2006; Diamond and Arabzadeh, 2013), instead of diminishing sensibility by the induction of response adaptation, may facilitate the detection of stimuli that appear surprisingly during the exploration by the activation of cortical properties.

\section{References}

Adorján P, Piepenbrock C, Obermayer K (1999) Contrast adaptation and infomax in visual cortical neurons. Rev Neurosci 10:181-200.
Ahissar E, Sosnik R, Bagdasarian K, Haidarliu S (2001) Temporal frequency of whisker movement: II. Laminar organization of cortical representations. J Neurophysiol 86:354-367.

Ahissar E, Sosnik R, Haidarliu S (2000) Transformation from temporal to rate coding in a somatosensory thalamocortical pathway. Nature 406:302-306.

Ahissar E, Zacksenhouse M (2001) Temporal and spatial coding in the rat vibrissal system. Prog Brain Res 130:75-87.

Ayala YA, Malmierca MS (2018) The effect of inhibition on stimulusspecific adaptation in the inferior colliculus. Brain Struct Funct 223:1391-1407.

Bale MR, Maravall M (2018) Organization of sensory feature selectivity in the whisker system. Neuroscience 368:70-80.

Barros-Zulaica N, Castejon C, Nuñez A (2014) Frequency-specific response facilitation of supra and infragranular barrel cortical neurons depends on NMDA receptor activation in rats. Neuroscience 281:178-194.

Berg RW, Kleinfeld D (2003) Vibrissa movement elicited by rhythmic electrical microstimulation to motor cortex in the aroused rat mimics exploratory whisking. J Neurophysiol 90:2950-2963.

Carro E, Nuñez A, Busiguina S, Torres-Aleman I (2000) Circulating insulin-like growth factor I mediates effects of exercise on the brain. J Neurosci 20:2926-2933.

Carvell GE, Simons DJ (1990) Biometric analyses of vibrissal tactile discrimination in the rat. J Neurosci 10:2638-2648.

Castro-Alamancos MA (2004) Absence of rapid sensory adaptation in neocortex during information processing states. Neuron 41: 455-464.

Castro-Alamancos MA (2009) Cortical up and activated states: implications for sensory information processing. Neuroscientist 15: 625-634.

Castro-Alamancos MA, Bezdudnaya T (2015) Modulation of artificial whisking related signals in barrel cortex. J Neurophysiol 113:12871301.

Chung S, Li X, Nelson SB (2002) Short-term depression at thalamocortical synapses contributes to rapid adaptation of cortical sensory responses in vivo. Neuron 34:437-446.

Citri A, Malenka RC (2008) Synaptic plasticity: multiple forms, functions, and mechanisms. Neuropsychopharmacology 33:18-41.

Curtis JC, Kleinfeld D (2009) Phase-to-rate transformations encode touch in cortical neurons of a scanning sensorimotor system. Nat Neurosci 12:492-501.

Dan Y, Poo MM (2004) Spike timing-dependent plasticity of neural circuits. Neuron 44:23-30.

de Kock CP, Sakmann B (2009) Spiking in primary somatosensory cortex during natural whisking in awake head-restrained rats is cell-type specific. Proc Natl Acad Sci U S A 106:16446-16450.

Dealy RS, Tolhurst DJ (1974) Is spatial adaptation an after-effect of prolonged inhibition? J Physiol 241:261-270.

Derdikman D, Yu C, Haidarliu S, Bagdasarian K, Arieli A, Ahissar E (2006) Layer-specific touch-dependent facilitation and depression in the somatosensory cortex during active whisking. J Neurosci 26:9538-9547.

Diamond ME, Arabzadeh E (2013) Whisker sensory system: from receptor to decision. Prog Neurobiol 103:28-40.

Díaz-Quesada M, Maravall M (2008) Intrinsic mechanisms for adaptive gain rescaling in barrel cortex. J Neurosci 28:696-710.

Díez-García A, Barros-Zulaica N, Nunez A, Buno W, Fernandez de Sevilla D (2017) Bidirectional hebbian plasticity induced by lowfrequency stimulation in basal dendrites of rat barrel cortex layer 5 pyramidal neurons. Front Cell Neurosci 11:8.

Dragoi V, Sharma J, Miller EK, Sur M (2002) Dynamics of neuronal sensitivity in visual cortex and local feature discrimination. Nat Neurosci 5:883-891.

Ego-Stengel V, Shulz DE, Haidarliu S, Sosnik R, Ahissar E (2001) Acetylcholine-dependent induction and expression of functional plasticity in the barrel cortex of the adult rat. J Neurophysiol 86:422-437.

Eriksson J, Villa AE (2005) Event-related potentials in an auditory oddball situation in the rat. Biosystems 79:207-212. 
Feldmeyer D, Brecht M, Helmchen F, Petersen CC, Poulet JF, Staiger JF, Luhmann HJ, Schwarz C (2013) Barrel cortex function. Prog Neurobiol 103:3-27.

Ganmor E, Katz Y, Lampl I (2010) Intensity-dependent adaptation of cortical and thalamic neurons is controlled by brainstem circuits of the sensory pathway. Neuron 66:273-286.

Grant RA, Mitchinson B, Fox CW, Prescott TJ (2009) Active touch sensing in the rat: anticipatory and regulatory control of whisker movements during surface exploration. J Neurophysiol 101:862874.

Gruart A, Leal-Campanario R, López-Ramos JC, Delgado GJ (2015) Functional basis of associative learning and its relationships with long-term potentiation evoked in the involved neural circuits: lessons from studies in behaving mammals. Neurobiol Learn Mem 124:3-18.

Hartings JA, Temereanca S, Simons DJ (2003) State-dependent processing of sensory stimuli by thalamic reticular neurons. J Neurosci 23:5264-5271.

Hellweg FC, Schultz W, Creutzfeldt OD (1977) Extracellular and intracellular recordings from cat's cortical whisker projection area: thalamocortical response transformation. J Neurophysiol 40:463479.

Heynen AJ, Bear MF (2001) Long-term potentiation of thalamocortical transmission in the visual cortex in vivo. J Neurosci 21:98019813.

Higley MJ, Contreras D (2003) Nonlinear integration of sensory responses in the rat barrel cortex: an intracellular study in vivo. $J$ Neurosci 23:10190-10200.

Higley MJ, Contreras D (2006) Balanced excitation and inhibition determine spike timing during frequency adaptation. J Neurosci 26:448-457.

Jadhav SP, Wolfe J, Feldman DE (2009) Sparse temporal coding of elementary tactile features during active whisker sensation. Nat Neurosci 12:792-800.

Kaczmarek L, Kossut M, Skangiel-Kramska J (1997) Glutamate receptors in cortical plasticity: molecular and cellular biology. Physiol Rev 77:217-255.

Katz Y, Heiss JE, Lampl I (2006) Cross-whisker adaptation of neurons in the rat barrel cortex. J Neurosci 26:13363-13372.

Khatri V, Bruno RM, Simons DJ (2009) Stimulus-specific and stimulus-nonspecific firing synchrony and its modulation by sensory adaptation in the whisker-to-barrel pathway. J Neurophysiol 101:2328-2338.

Khatri V, Hartings JA, Simons DJ (2004) Adaptation in thalamic barreloid and cortical barrel neurons to periodic whisker deflections varying in frequency and velocity. J Neurophysiol 92:3244-3254.

Kheradpezhouh E, Adibi M, Arabzadeh E (2017) Response dynamics of rat barrel cortex neurons to repeated sensory stimulation. Sci Rep 7:11445.

Kleinfeld D, Ahissar E, Diamond ME (2006) Active sensation: insights from the rodent vibrissa sensorimotor system. Curr Opin Neurobiol 16:435-444.

Kleinfeld D, Deschênes M (2011) Neuronal basis for object location in the vibrissa scanning sensorimotor system. Neuron. 72:455-468.

Lak A, Arabzadeh E, Diamond ME (2008) Enhanced response of neurons in rat somatosensory cortex to stimuli containing temporal noise. Cereb Cortex 18:1085-1093.

Maravall M, Alenda A, Bale MR, Petersen RS (2013) Transformation of adaptation and gain rescaling along the whisker sensory pathway. PLoS One 8:e82418.

Maravall M, Petersen RS, Fairhall AL, Arabzadeh E, Diamond ME (2007) Shifts in coding properties and maintenance of information transmission during adaptation in barrel cortex. PLoS Biol 5:e19.

Martin-Cortecero J, Nuñez A (2014) Tactile response adaptation to whisker stimulation in the lemniscal somatosensory pathway of rats. Brain Res 1591:27-37.

Moore JJ, Ravassard PM, Ho D, Acharya L, Kees AL, Vuong C, Mehta MR (2017) Dynamics of cortical dendritic membrane potential and spikes in freely behaving rats. Science 355:eaaj 1497.
Mysoet J, Dupont E, Bastide B, Canu MH (2015) Role of IGF-1 in cortical plasticity and functional deficit induced by sensorimotor restriction. Behav Brain Res 290:117-123.

Nabavi S, Fox R, Proulx CD, Lin JY, Tsien RY, Malinow R (2014) Engineering a memory with LTD and LTP. Nature 511:348-352.

Nishijima T, Piriz J, Duflot S, Fernandez AM, Gaitan G, GomezPinedo U, Verdugo JM, Leroy F, Soya H, Nuñez A, Torres-Aleman I (2010) Neuronal activity drives localized blood-brain-barrier transport of serum insulin-like growth factor-I into the CNS. Neuron 67:834-846.

Nuñez A, Carro E, Torres-Aleman I (2003) Insulin-like growth factor I modifies electrophysiological properties of rat brain stem neurons. J Neurophysiol 89:3008-3017.

Nuñez A, Domínguez S, Buño W, Fernández de Sevilla D (2012) Cholinergic-mediated response enhancement in barrel cortex layer V pyramidal neurons. J Neurophysiol 108:1656-1668.

Paxinos G, Franklin KB (2003) The mouse brain in stereotaxic coordinates. Amsterdam: Elsevier.

Perkel DH, Moore GP, Segundo JP (1963) Continuous-time simulation of ganglion nerve cells in Aplysia. Biomed Sci Instrum 1:347357.

Rahman J, Berger T (2011) Persistent activity in layer 5 pyramidal neurons following cholinergic activation of mouse primary cortices. Eur J Neurosci 34:22-30.

Rotwein P, Burgess SK, Milbrandt JD, Krause JE (1988) Differential expression of insulin-like growth factor genes in rat central nervous system. Proc Natl Acad Sci U S A 85:265-269.

Sanchez-Vives MV, McCormick DA (2000) Cellular and network mechanisms of rhythmic recurrent activity in neocortex. Nat Neurosci 3:1027-1034.

Scheppach C (2016) High- and low-conductance NMDA receptors are present in layer 4 spiny stellate and layer $2 / 3$ pyramidal neurons of mouse barrel cortex. Physiol Rep 4:e13051.

Segundo JP, Moore GP, Stensaas LJ, Bullock TH (1963) Sensitivity of neurones in Aplysia to temporal pattern of arriving impulses. $J$ Exp Biol 40:643-667.

Sharpee TO, Sugihara H, Kurgansky AV, Rebrik SP, Stryker MP, Miller KD (2006) Adaptive filtering enhances information transmission in visual cortex. Nature 439:936-942.

Sosnik R, Haidarliu S, Ahissar E (2001) Temporal frequency of whisker movement: I. Representations in brain stem and thalamus. $J$ Neurophysiol 86:339-353.

Steriade M (1993) Cellular substrates of brain rhythms, electroencephalography. In: Basic principles, clinical applications, and related fields (Niedermeyer E, Lopes Da Silva F, eds) pp 27-62. Baltimore, MD: Williams \& Wilkins.

Szwed M, Bagdasarian K, Ahissar E (2003) Encoding of vibrissal active touch. Neuron 40:621-630.

Thomson AM (2000) Facilitation, augmentation and potentiation at central synapses. Trends Neurosci 23:305-312.

Trueba-Sáiz A, Cavada C, Fernandez AM, Leon T, González DA, Fortea Ormaechea J, Lleó A, Del Ser T, Nuñez A, Torres-Aleman I (2013) Loss of serum IGF-I input to the brain as an early biomarker of disease onset in Alzheimer mice. Transl Psychiatry 3:e330.

Ulanovsky N, Las L, Nelken I (2003) Processing of low-probability sounds by cortical neurons. Nat Neurosci 6:391-398.

Villa AE, Asai Y, Segundo JP (2007) Influence of the temporal distribution of electric pulses on transcallosal single unit responses. Biosystems 89:143-153.

von Heimendahl M, Itskov PM, Arabzadeh E, Diamond ME (2007) Neuronal activity in rat barrel cortex underlying texture discrimination. PLoS Biol 5:e305.

Yamaguchi F, Itano T, Mizobuchi M, Miyamoto O, Janjua NA, Matsui H, Tokuda M, Ohmoto T, Hosokawa K, Hatase O (1990) Insulin-like growth factor I (IGF-I) distribution in the tissue and extracellular compartment in different regions of rat brain. Brain Res 533:344347.

Yamashita T, Petersen C (2016) Target-specific membrane potential dynamics of neocortical projection neurons during goal-directed behavior. eLife 5:e15798. 